\title{
BMJ Open Doctors admitted to a Physicians' Health Program: a comparison of self-referrals versus directed referrals
}

\author{
María Dolores Braquehais, ${ }^{1,2}$ Sergi Valero, ${ }^{2}$ Miquel Jordi Bel, ${ }^{1,2}$ \\ María Cecilia Navarro, ${ }^{1}$ Josep Lluís Matalí,, ${ }^{1}$ Viviana Nasillo, ${ }^{2}$ Jaume Padrós, ${ }^{1}$ \\ Antoni Arteman, ${ }^{1}$ Eugeni Bruguera, ${ }^{1,2}$ Miquel Casas ${ }^{1,2}$
}

To cite: Braquehais MD, Valero S, Bel M J, et al. Doctors admitted to a Physicians' Health Program: a comparison

of self-referrals versus directed referrals. BMJ Open 2014;4:e005248.

doi:10.1136/bmjopen-2014005248

- Prepublication history and additional material for this paper is available online. To view these files please visit the journal online (http://dx.doi.org/10.1136/ bmjopen-2014-005248).

Received 12 March 2014 Revised 18 June 2014 Accepted 19 June 2014

CrossMark

\footnotetext{
${ }^{1}$ Integral Care Program for Sick Health Professionals, Galatea Clinic, Galatea Foundation, Col-legi Oficial de Metges de Barcelona,

Barcelona, Spain

${ }^{2}$ Department of Psychiatry and Legal Medicine, Hospital Universitari Vall d'Hebron, CIBERSAM, Universitat Autònoma de Barcelona, Barcelona, Spain
}

Correspondence to Dr María Dolores Braquehais; mdbraquehais@vhebron.net

\section{ABSTRACT}

Objective: To compare the profile of doctors with mental disorders admitted to a Physicians' Health Program (PHP) depending on their type of referral. Design: Retrospective chart review.

Method: We analysed 1545 medical records of doctors admitted to the Barcelona PHP (PAIMM) from 1 February 1998 to 31 December 2012.

Results: Most doctors (83.2\%) were self-referred to the programme. Patients non-self-referred were older $(\bar{x}=55$ vs $\bar{x}=49.6$ years; $t=6.96, p<0.01)$ than those self-referred and there were more men $(68.3 \%)$ than women (45.8\%; $\mathrm{OR}=0.39 ; 95 \% \mathrm{Cl} 0.29$ to 0.52 ). Selfreferrals were more frequent among patients with nonaddictive disorders ( $84.6 \%$ vs $15.4 \%$; $\mathrm{OR}=4.52 ; 95 \%$ $\mathrm{Cl} 3.23$ to 28.45). Self-referred patients needed less inpatient admissions ( $16.8 \%$ vs $30.9 \%$; $O R=2.22 ; 95 \%$ $\mathrm{Cl} 1.63$ to 3.01) and the length of their treatment episodes was shorter ( $\overline{\mathrm{x}}=24.3$ vs $\overline{\mathrm{x}}=32.4$ months; $\mathrm{t}=3.34 ; \mathrm{p}<0.01$ ). Logistic regression showed a significant model $\left(\chi^{2}=67.52 ; \mathrm{df}=3 ; p<0.001\right)$. Age, gender and diagnosis were statistically associated with type of referral to the programme.

Conclusions: Type of referral to a PHP may be influenced not only by sick doctors' personal traits but also by each programme's design and how it is perceived by service users. Our findings should be taken into account when designing treatment and preventive interventions for this professional group.

\section{INTRODUCTION}

The first specific programmes for physicians (Physicians' Health Programs, PHPs) suffering from mental disorders (ie, sick doctors) were developed in the USA since the late 1970 s with the main aim of preventing malpractice behaviours, mainly related to drug and alcohol misuse. ${ }^{1-3}$ Programmes with intensive preventive and treatment interventions were developed later on in Canada, ${ }^{4}$ Australia $^{5}$ and the UK. ${ }^{6}$ Norway $^{7}$ and Switzerland $^{8}$ mainly offer preventive and counselling services for doctors. Some

\section{Strengths and limitations of this study}

- This is the first study comparing the profile of doctors treated at a Physicians' Health Program (PHP) depending on their type of referral. It is based on data from the Barcelona PHP.

- The results suggest that doctors who are male, older or suffering from addictions may have greater difficulties when asking for help from our Physicians' Health Program. These patients also require more clinical resources than those selfreferred.

- The main limitations of this study include the study design (a chart review) and the lack of information about clinical and other psychosocial variables that could be related to the referral type.

- Type of referral may be influenced by sick doctors' personal traits as well as by the specific nature of PHP programmes and how they are presented to users.

French regions are currently working to implement similar programmes for their practising physicians.

In Spain, PHPs (PAIME, in Spanish) were developed since 1998 and are ruled by the 'Colegio de Médicos' of each Spanish region. 'Colegios de Médicos' are institutions where all practising doctors in Spain need to be registered. They act as Medical Associations and Regulatory Bodies (or Medical Councils). Every 'Colegio de Médicos' in Spain offers to their registered physicians a PHP outpatient service. Nonetheless, there is only one PHP inpatient unit for all of the Spanish PHPs, currently located in Barcelona. The doctor-as-patient's last names are changed once he/she enters the programme in order to preserve confidentiality. Their real identity can only be disclosed without their consent if there is a threat to self or others. 
The Spanish PHP promotes voluntary treatment as well as enrolment for preventive interventions. Treatment becomes obligatory only when risk or evidence of practice difficulties are identified. Mandatory actions can oblige sick doctors to undergo psychiatric treatment; if they suffer from an addictive disorder, this includes proving abstinence once treatment has been completed. The final objective of all these interventions is to help sick doctors recover their personal well-being and help them go back safely to their professional practice.

The aim of this study is to compare the profile of doctors with mental disorders admitted to the PHP located in Barcelona (PAIMM, in Catalan) depending on their type of referral (self-referrals vs directed referrals). Our specific objectives were: (A) to compare the differences in age, gender and main diagnosis at admission; (B) to compare the mean length of their treatment episodes and the number of inpatient admissions during their treatment process; and, $(\mathrm{C})$ to discuss the preventive and treatment implications of our findings.

To the best of our knowledge, this is the first study that analyses the traits and clinical needs of those who have entered a PHP. This could help identify which doctors may present greater difficulties in asking for help and should be taken into account when designing preventive and treatment strategies for them.

\section{METHODS}

\section{Setting}

Medical records of physicians referred from the 'Colegio de Médicos' of Barcelona to the Barcelona PHP were selected. We classified the types of referrals into two groups: self-referrals versus directed referrals. We distinguished

1. Self-referrals: patients self-referred to the programme.

2. Directed referrals

2.1. Induced referrals: although the patients call the programme to ask for help, referrals are encouraged or induced by managers, colleagues or relatives.

2.2. Referrals after confidential information received by their 'Colegio de Médicos' about practice problems.

2.3. Referrals after a formal report received by the 'Colegio de Médicos' due to practice difficulties.

If, after a clinical evaluation, a mental disorder is identified, the sick doctor is offered outpatient or inpatient treatment depending on the severity of each case.

\section{Participants}

A retrospective chart review of clinical and sociodemographic data was conducted on 1545 medical records of physicians admitted to the Barcelona PHP from 1 February 1998 to 31 December 2012.

\section{Ethics}

In Spain, neither approval by an Ethics Committee nor informed consents from patients are needed to conduct a chart review. Nevertheless, the principles outlined in the Declaration of Helsinki ${ }^{10}$ were followed during this research.

\section{Clinical and sociodemographic variables}

The variables age, gender and type of referral were selected. The main diagnosis at admission, according to the DSM-IV criteria, ${ }^{11}$ was obtained from each medical record. We grouped the main diagnoses into two groups (substance use disorders and non-substance use disorders).

Other clinical variables were related to the time (in months) the patients were treated in the programme and to the presence of inpatient admissions during their follow-up period.

\section{Statistical analyses}

$\chi^{2}$ Tests were used to compare dichotomous variables between groups. ORs with $95 \%$ CIs were used to analyse the relationship between binary variables. Student $t$ tests were used to compare quantitative variables. All hypotheses tests were two-tailed and conducted with an $\alpha$ of 0.05 .

A logistic regression analysis was conducted to analyse the type of referral using age, gender and main diagnosis as independent factors. All analyses were performed using SPSS V.20 (Chicago, Illinois, USA).

\section{RESULTS}

Most doctors (83.2\%) were self-referred to the programme. Doctors with other types of referrals were older $(\overline{\mathrm{x}}=55.0 ; \quad \mathrm{SD}=11.68$ years $\quad$ vs $\overline{\mathrm{x}}=49.6 ; \quad \mathrm{SD}=11.97$ years; $\mathrm{t}=6.96, \quad \mathrm{p}<0.01)$. More men $(68.3 \%)$ than women $(45.8 \%)$ were not self-referred $(\mathrm{OR}=0.39 ; 95 \%$ CI 0.29 to 0.52). Self-referrals were more frequent among patients with non-substance use disorders $(84.6 \%)$ than in those with addictive disorders $(15.4 \%)$, with this difference being statistically significant $(\mathrm{OR}=4.52 ; 95 \%$ CI 3.23 to 28.45 ).

Self-referred patients needed inpatient admissions less frequently (16.8\%) compared with those with nonvoluntary referrals $(30.9 \%)$; once again, such differences were statistically significant ( $\mathrm{OR}=2.22 ; 95 \%$ CI 1.63 to 3.01$)$. The length of treatment episodes was shorter for those identified as self-referred (mean=24.3; $\mathrm{SD}=28.42$ months vs mean $=32.4 ; \mathrm{SD}=32.4$ months; $\mathrm{t}=3.34 ; \mathrm{p}<0.01$ ).

Logistic regression analysis showed a significant model $\left(\chi^{2}=67.52 ; \mathrm{df}=3 ; \mathrm{p}<0.001\right)$. Age, gender and diagnosis were statistically associated with the type of referral (see table 1).

\section{DISCUSSION}

This is the first study that compares the profile of doctors treated at a PHP according to their type of referral. 
Table 1 Logistic regression analysis output of type of referral

\begin{tabular}{llllll}
\hline Variables & B & Wald & Significance & OR & $(95 \%$ CI) \\
\hline Age & 0.025 & 9.970 & $<0.01$ & 1.025 & $(1.010$ to 1.042$)$ \\
Gender (M/F) & -0.557 & 9.385 & $<0.01$ & 0.573 & $(0.401$ to 0.818$)$ \\
SUD vs Non-SUD & -1.331 & 59.031 & $<0.001$ & 0.264 & $(0.188$ to 0.371$)$ \\
Constant & 0.298 & & & & \\
\hline Self-referral=1; control group=0. & & & & \\
SUD, substance use disorders. & & & & & \\
\end{tabular}

Cross-country comparisons between PHPs are difficult. Data about other PHPs in the USA ${ }^{12}$ and Canada ${ }^{13}$ mainly provide information about non-voluntarily referred sick doctors as a result of substance use disorders. In the UK, the Practitioner Health Program ${ }^{14}$ treated 554 practitioners and 20 other professionals during the 2008-2011 period, $85 \%$ for mental disorders, $28 \%$ for substance use disorders and $17 \%$ for physical problems. Regretfully, no information was available regarding the ways of access to this programme. However, 29\% of patients needed an intervention from the regulatory body. ${ }^{14}$ In Switzerland, ${ }^{8}$ during a 3-year period, 80 patients were treated at the ReMed program mainly for burn-out and depression (43\%) followed by practice and everyday life problems (32\%) and only $13 \%$ for addictive behaviours. In Norway, ${ }^{7}$ after analysing the data of 227 doctors who had come for counselling to a specific programme designed for them, $73 \%$ were in need of treatment for anxiety and depression. When analysing the ways of accessing the programme, only $45 \%$ were self-referred. No information for cases needing mandatory treatment is available from Switzerland and Norway PHPs. ${ }^{7}$

Although PHPs' designs may be different, mandatory actions in different countries have in common that once practice problems are identified, sick doctors are obliged to undergo psychiatric treatment and if they suffer from an addictive disorder they have to remain abstinent. Otherwise, their license to practise will be temporarily or definitively suspended. ${ }^{12-14}$

In our PHP, we have observed that doctors are more likely to be self-referred when they are women and suffer from non-substance use disorders. Those self-referred are also younger when compared to those whose way of access has been non-voluntary. These results suggest that doctors with addiction problems tend to delay seeking help, maybe because they fear the consequences of their demand. ${ }^{15}$ In line with other studies, women physicians are more likely to ask for help when they suffer from mental distress than their male counterparts. ${ }^{16}$

However, the specific nature of our PHP should be taken into account when interpreting our results. Patients may feel encouraged to seek help in our programme where voluntary referrals are promoted and mandatory actions are only applied to cases at risk or in evidence of practice problems. Therefore, the type of referral may be influenced not only by the sick doctors' problems but also by each PHP's design including how it is presented to service users.

Our group has recently suggested that a non-punitive philosophy for sick doctors may encourage help seeking among them. Since it was created in 1998, self-referrals to the Barcelona PHP have grown from $81.3 \%$ during the first years to $91.5 \%$ in the last period. ${ }^{17}$

In the present study, doctors who came voluntarily had shorter treatment episodes and needed less inpatient admissions than those with other forms of referrals. These findings suggest a better prognosis for those users seeking help voluntarily compared with those forced to enter the programme.

The main limitations of this study are: (A) it is a retrospective chart review; (B) there was only one main diagnosis for each patient not obtained after a structured interview, such as the Structured Clinical Interview for DSM Disorders (SCID-I) $;^{18}$ and (C) the lack of personal and ecological variables from the users, as no data were available in terms of personality traits and/or other psychosocial aspects possibly related to the type of referral to our programme.

Despite its limitations, the results of this study give some clues when attempting to identify sick doctors with greater difficulties in asking for help from our PHP. Destigmatising doctors with addictions, enhancing help seeking among male physicians and encouraging selfidentification of mental disorders from the early stages of their medical training could become effective preventive strategies within this professional group.

On the other hand, our follow-up observations need to be taken into account from an organisational perspective, as doctors with mental or emotional distress who are more reluctant to ask for help from our PHP require additional clinical resources than those who are motivated with their treatment.

Results from this study should be interpreted cautiously, especially when trying to generalise our findings to other settings. The specific philosophy of our PHP is one aspect to be considered. However, some features of sick doctors with difficulties in seeking help may be similar to those observed in other PHPs. Therefore, preventive and treatment strategies for sick doctors in all countries may benefit from taking into account these findings.

Acknowledgements The authors would like to thank Dr Andrew Tresidder for his assistance with the English edition of this manuscript. They would also like to thank the members of the Galatea Foundation and of the Col.legi de 
Metges de Barcelona for their constant support in the development and maintenance of our Physicians' Health Program.

Contributors MDB, the main researcher, was involved in all phases of the study, including study design, literature search, conduct of the study, data analysis and final article write up. SV performed the statistical analysis and reviewed the manuscript. VN edited the paper in English. MJB, MCN, JP, $\mathrm{JLM}, \mathrm{AA}, \mathrm{EB}$ and $\mathrm{MC}$ contributed to the critical review of the paper. All authors approved the final version of the manuscript.

Funding This research received no specific grant from any funding agency in the public, commercial or not-for-profit sector.

Competing interests None.

Ethics approval In Spain, no approval by an Ethics Committee, nor informed consents from patients, are needed to conduct a chart review.

Provenance and peer review Not commissioned; externally peer reviewed.

Data sharing statement No additional data are available.

Open Access This is an Open Access article distributed in accordance with the Creative Commons Attribution Non Commercial (CC BY-NC 4.0) license, which permits others to distribute, remix, adapt, build upon this work noncommercially, and license their derivative works on different terms, provided the original work is properly cited and the use is non-commercial. See: http:// creativecommons.org/licenses/by-nc/4.0/

\section{REFERENCES}

1. Talbott GD, Martin CA. Treating impaired physicians: fourteen keys to success. Va Med 1986;113:95-9.

2. DuPont RL, McLellan AT, Carr G, et al. How are addicted physicians treated? A national survey of Physician Health Programs. J Subst Abuse Treat 2009;37:1-7.

3. Dupont RL, Skipper GE. Six lessons from state physician health programs to promote long-term recovery. J Psychoac Drugs 2012:44:72-8.
4. Puddester DG. Canada responds: an explosion in doctors' health awareness, promotion and intervention. Med $J$ Aust 2004;181:386-7.

5. Jurd SM. Helping addicted colleagues. Med J Aust 2004;181:400-2

6. Oxley JR. Services for sick doctors in the UK. Med J Aust 2004;181:388-9.

7. Ro KEl, Gude T, Aasland OG. Does a self-referral counselling program reach doctors in need of help? A comparison with the general Norwegian doctor workforce. BMC Public Health 2007;7:36.

8. Hegenbarth C. Rescuing doctors in distress. CMAJ 2011;183:E153-4.

9. Bosch X. First impaired physicians therapy program appears to be successful in Spain. JAMA 2000;283:3186-7.

10. World Medical Association. World Medical Association Declaration of Helskini. Ethical principles for Medical Research Involving Human Subjects. JAMA 2013;310:2191-4.

11. American Psychiatric Associations. Diagnostic and statistical manual of mental disorders, fourth edition, text revision (DSM-IV-TR). Vol 1. Arlington, VA: American Psychiatric Association, 2000.

12. McLellan AT, Skipper GS, Campbell M, et al. Five years outcomes in a cohort study of physicians treated for substance use disorders in the United States. BMJ 2008;337:a2038.

13. Brewster JM, Kaufmann IM, Hutchison S, et al. Characteristics and outcomes of doctors in a substance dependence monitoring programme in Canada: prospective descriptive study. BMJ 2008;337:a2098.

14. NHS Practitioner Health Programme [Internet]. London: National Health Service: 2011 report, 2011 [cited 2014 May 14]. Version No: 3. http://php.nhs.uk/wp-content/uploads/sites/26/2013/11/PHP-Three -Year-Report-Final-Version-3.pdf

15. Carinci A, Christo PJ. Physician impairment: is recovery feasible? Pain Phys 2009;12:487-91.

16. Firth-Cozens J. Doctors with difficulties: why so few women? Postgrad Med J 2008;84:318-20.

17. Braquehais MD, Valero $\mathrm{S}$, Matalí JL, et al. Promoting voluntary help-seeking among doctors with mental disorders. Int J Occup Med Environ Health 2014;27:1-9.

18. First MB, Spitzer RL, Williams JBW, et al. Structured clinical interview for DSM-IV (SCID-I) (user's guide and interview), research version, non-patient edition. New York: Biometrics Research Department, New York Psychiatric Institute, 1995 